\section{World enough and time}

\author{
David E.H. Jones
}

The World of Mathematics: A Small Library of the Literature of Mathematics from A'h-mosé the Scribe to Albert Einstein. Commentaries and notes by James R. Newman. Tempus Books, 16011 NE 36th Way, Box 97017, Redmond, Washington 98073-9717: 1956/1988. Four volumes, pp.2,448 plus indexes. Distributed by Harper \& Row, hbk \$99.95, pbk\$50.

IN 1940 James R. Newman, a lawyer and writer who had trained as a mathematician, began to assemble a popular historical anthology of mathematical writings. $\mathrm{He}$ reckoned it might take him two years. Fifteen years later he delivered the million-word manuscript to his publisher: 133 entries, each with a brief introduction and biography of its author. The World of Mathematics finally appeared, in four volumes, in 1956. It was immediately successful - a classic of mathematical popularization. Now Tempus Books has reissued it, still in four volumes but this time in paperback as well as hardback form. How does it read in 1989 ?

The coverage, eclectic from the first, is beginning in parts to date. The broad historical background of mathematics is still excellent; the sections dealing with mathematics in the physical and social worlds, and with the bases of statistics, stand up for the most part remarkably well. But many of the entries concerned with pure mathematics and its cultural relevance would certainly have been reconsidered by Newman today. The intellectual level remains demanding but not intimidating: appropriate for the enquiring non-mathematician, or the mathematician off-duty. About 20 per cent of the entries are drawn from the research literature, or at least the primary presentation of original work; 30 per cent are educational or polemical pieces; 40 per cent are popularizations of established mathematics; and 10 per cent are stories, or whimsical or discursive essays.

The charm of a good historical anthology is the variety of outlooks and challenges it presents. Here is Francis Galton in 1869 discussing hereditary genius, blandly contravening all the principles of social justice by proving that some people are inherently many times brighter than others. Here is Malthus's famous essay of 1798 on population, condemning most of mankind for most of time to unavoidable misery - and where's the flaw in his argument? Here is Alan Turing in 1950 on whether a machine might think, an amazingly modern essay which still reads cogently after nearly 40 years of massive developments in computing. Newman was clearly a connoisseur of good literary style. Each of his selections can be read purely for pleasure, even without bothering to follow its argument. Anybody who reads the scientific literature should enjoy the book for this alone; anyone who writes it will probably blush for shame.

The whole huge compilation is far too big to take in at a sitting. It is a book for extended browsing, or a rather eccentric work of reference. I like best the entries dealing with mathematics in the real world. Lanchester on the mathematics of warfare, showing how Nelson's brilliant strategy at Trafalgar closely approached a theoretical optimum; Moseley's account of the X-ray identification of atomic number, probably his last paper before his tragic and pointless death at Gallipoli; Bernard Shaw on gambling and insurance - a departure from his usual concerns, but characteristically spirited and surprisingly sensible; John von Neumann on the workings of the neuron, and the analogy between the brain and the digital computer.

\section{Down to earth}

\section{Robert J. Devoy}

Quaternary Geology for Scientists and Engineers. By John A. Catt. Ellis Horwood: 1988. Pp.340. £39.50, \$69.95.

QUATERNARY geology (or, in a less partisan sense, Quaternary science) has long been the Cinderella of the earth sciences, attracting little attention as a discipline except from small national bands of enthusiasts. It is against this background that John Catt has produced a compact book of seven chapters that goes some way towards helping to redress the imbalance. The text presents information in a simple, practically orientated and narrative style, describing some of the subject's study themes, methodologies and techniques.

In some quarters, the book may not be received unreservedly. It is in places too much a catalogue of dry factual material. The treatment may also be viewed as overly selective and idiosyncratic, a situation which may have arisen from the author's aim of principally satisfying the needs of practical field scientists rather than those of specialists.

Against these criticisms, it should be remembered that non-specialists have to start somewhere. Despite the introductory approach the volume is not intended to be a definitive textbook, and the basic descriptive form will suit such non-specialist readers. Instead of a comprehensive overview, we have rather a helpful collection of working principles and definitions set
This new edition has not been reprinted. A copy of the 1956 Simon and Schuster publication has been optically scanned and digitally reset (the stupefying intellectual triviality of the tasks that occupy most modern computers would have saddened Turing and von Neumann). The index has been slightly modified; I have spotted just two words of additional text. The publishers have thus missed the opportunity to remedy the most infuriating omission of the first edition: the lack of bibliographical references to the entries. Some can be placed from Newman's commentaries, but many are quite free-floating. It is quite impossible to stand in proper relationship to a piece of writing if you don't know in what context, or crucially when, it was written. The annoying detective work needed to pin down each entry from Newman's introduction to it, or from other sources, is almost the only unpleasing feature of this marvellous book.

David E.H. Jones is guest staff member in the Department of Physical Chemistry, University of Newcastle upon Tyne, Newcastle upon Tyne NE1 7RU, UK.

within the framework of Quaternary data.

Quaternary science is an interdisciplinary and applied area of research. Its historical origin in nineteenth-century geology, coupled with the subsequent growth of specialisms, has too often led to a view of the subject as preoccupied with stratigraphy, gravels and an arid ordering of glacial-interglacial stages. It is refreshing, therefore, to see included here accounts of relevant specialisms which are clearly rooted in the aims and concerns of Quaternary studies. Geomorphology, soil science and dating techniques are all given chapter status alongside the coverage of basic stratigraphic approaches. A further innovation is the inclusion of chapters on mapping techniques and on the economic and applied importance of the Quaternary studies approach.

Regrettably some relevant areas, such as sea-level studies and palaeoecology, receive minimal and less than up-to-date treatment. Together with deficiencies in referencing the more advanced literature, these lacunae possibly reflect the author's own interests as well as the rapid advances in the literature concerned. Nonetheless the book's strengths outweigh its weaknesses. It contains an innovative and authoritative view of Quaternary science, and will be of great practical value to earth scientists.

Robert J. Devoy is a Senior Lecturer in the Department of Geography. University College Cork, Ireland.

- Newly published by Unwin Hyman is Chemical Fundamentals of Geology, by Robin Gill, intended for geology students and others wanting to get to grips with 'geo-relevant' chemistry. 